\title{
As conferências públicas no projeto de instrução pública e organização do ensino de Condorcet
}

Eduardo Antônio Jordão

Professor-Coordenador da Prefeitura Municipal de Americana/SP Doutorando em Educação pela UNICAMP

\section{Resumo}

O texto situa em seu contexto as Conferências Públicas e apresenta o seu papel no projeto de Instrução Pública e Organização do Ensino, proposto por Jean Antoine Nicolas de Caritat, marquês de Condorcet (1743-1794), que deu origem ao decreto sobre Instrução Pública aprovado na Assembléia Nacional da França Revolucionária em 1792. Ao final, caberá uma breve comparação entre os objetivos das Conferências Públicas dispostos por Condorcet com o recente programa Escola da Família, do governo do Estado de São Paulo, para evidenciar o contraste entre duas políticas liberais para a educação.

Palavras-chave: Educação; Condorcet; Conferências Públicas.

\begin{abstract}
The essay places in context the Public conferences and presented his paper on the design of Public Instruction and Education Organization, proposed by Jean Antoine Nicolas de Caritat, Marquis de Condorcet (1743-1794), which led to the decree on Public Instruction approved National Assembly of Revolutionary France in 1792. In the end, it will be a brief comparison between the objectives of Public Conferences arranged by Condorcet at the recent Family School program, the state government of St. Paul, to highlight the contrast between two liberal policies for education.
\end{abstract}

Key-words: Education; Condorcet; Public Conferences. 


\section{Introdução}

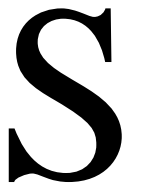

e na pena dos mais ilustres escritores do séc. XVIII é notável um fervilhar de ideias progressistas e emancipatórias em vários campos da vida humana, este mesmo iluminismo ou esclarecimento não encontra correspondência na realidade educacional daquela época. Seja na França ou na Inglaterra, a situação do ensino elementar, e mesmo o secundário, era bastante precária, geralmente confiado às escolas paroquiais, aos preceptores ou ainda a algumas mulheres sem muita instrução que reuniam em suas casas, sob pagamento, alunos de sua vizinhança para o aprendizado dos primeiros conhecimentos. O alcance desta educação, portanto, era limitado, quando muito não se confundia com filantropia ou formação moral a partir de alguma concepção religiosa. Como conclui Abbganano, essa caridade tinha pouca difusão e eficácia na formação das crianças (2001, p. 384). Os ensinos secundário e superior estavam em grande parte nas mãos das ordens religiosas, se não sob sua própria manutenção, ao menos sob influência dos seus mestres nas universidades seculares.

A educação é um dos temas de debate do século XVIII. Reconhecia-se a sua necessidade e utilidade, mas a divergência se assentava no seu alcance, financiamento e especificidade. Os projetos de educação universal receberam pouca acolhida prática, como os de Diderot e Condorcet. Voltaire e outros defendiam que o povo deveria ser guiado e não instruído para conquistar sua autonomia. A ingerência da monarquia quanto a este assunto e a falta de consenso entre as autoridades políticas encarregadas da educação são os principais fatores do contraste entre realidade educativa e riqueza de ideias vividas pelo séc. XVIII.

Com a Revolução, os dirigentes perceberam rapidamente a necessidade de uma reforma educacional. Diante das mudanças nas estruturas políticas e das instituições sociais, uma dupla expectativa se impôs à tarefa educativa: 1) educar um novo cidadão, para que a população adquirisse espírito cívico, diferente do vassalo ou escravo, e atuasse de 
maneira efetiva na vida social, garantindo a continuidade das reformas; 2) educar com base nos ideais de liberdade, igualdade e fraternidade, via filosofia das Luzes, que confiava sobremaneira no esclarecimento da e pela Razão, para que esta, a partir de suas faculdades judicativa e legislativa, se torne a guia e mestra das ações humanas.

A França revolucionária, portanto, demandava uma organização do ensino num sistema completo de instrução pública, a exemplo do que já vinha acontecendo com educação elementar na Alemanha reformada. Era preciso dar corpo a tal sistema, uniformizar o discurso oficial sobre educação para que os ideais da Revolução não somente fossem postos em prática, mas também para garantir a permanência de tais ideais nas gerações futuras.

Convém resgatar o percurso da Revolução que estabeleceu o Comitê responsável pela criação do sistema de ensino. Em junho de 1789, o Terceiro Estado ${ }^{1}$ separa-se do Parlamento Nacional em protesto ao peso dado ao seu voto, apesar de representar um número muito superior de súditos em relação aos outros dois estados. Ao declarar-se representante da nação, o Terceiro Estado constitui-se como Assembleia Nacional. Em julho, o rei cede e os outros dois estados se reúnem ao Terceiro, formando então a Assembleia Nacional Constituinte. Iniciaram-se inúmeros conflitos devido aos rumores de golpe por parte dos dois primeiros estados. Em mais um ato de ousadia, a Assembleia proclama a Declaração dos Direitos do Homem e do Cidadão. Até 1791, a situação permaneceu tensa na França, indo além do confronto político rumo aos conflitos armados entre os três estados.

Em setembro de 1791, a Assembleia promulgou uma Constituição que transformou o Poder Absoluto em Constitucional. Já em agosto de 1792, com a suspensão da monarquia e do governo de Luís XVI, é eleita uma

\footnotetext{
${ }^{1}$ Na época do Luís XVI, a França era dividida e organizada em Três Estados: o Primeiro Estado era formado pelo clero, o Segundo Estado, pela nobreza e o Terceiro Estado pelo restante da população, desde profissionais liberais, burgueses, industriais, artesãos e camponeses. A proporção de votos no Parlamento Nacional era de 300 deputados para o Primeiro e Segundo Estado e 600 assentos para o Terceiro. No entanto, o voto não era igualitário: ao Primeiro e Segundo Estados, dois votos, ao Terceiro, um.
} 
Convenção Nacional que tomaria conta dos rumos da Revolução e no mês seguinte houve a abolição do regime monárquico e a proclamação da República Francesa.

\section{Condorcet: sua inserção na Revolução e o Plano de Educação}

Condorcet, nesse movimento, participou da Assembleia como secretário e presidente, tendo uma postura em defesa do estabelecimento do regime republicano e também foi eleito para a Convenção Nacional. Em dezembro de 1791, é indicado para participar do Comitê de Instrução Pública, responsável por elaborar o sistema de ensino francês.

Condorcet é um pensador filiado ao ideário das Luzes. Era simpático às ideias econômicas liberais de Turgot, que lhe confiou em 1770 a inspeção geral da moeda. Foi amigo de D’Alambert e por seu intermédio conheceu Diderot, Voltaire e outros enciclopedistas, reunindo em torno de si um grupo de partidários das ideias revolucionárias. O projeto de Instrução Pública foi elaborado a partir da tese da perfectibilidade crescente do homem, interrompida por vezes em épocas de tirania ou de superstição. Esta é uma marca do seu otimismo em relação à tarefa educativa.

A instrução nacional na República Francesa teria por objetivo instaurar a igualdade e a liberdade entre os homens, reconhecidas por lei, mas não praticadas pela sociedade. A educação deve ser igual e universal, o mais completa possível, dar a todos o máximo de instrução e não recusar a ninguém o seu grau mais elevado. A liberdade seria garantida: 1) pelo ensino de coisas verdadeiras nos estabelecimentos de ensino, distinto das antigas superstições; 2) os estabelecimentos seriam, o quanto possível, independentes da autoridade política. (Condorcet, 1943, p. 8)

Enfim, nenhum poder público deve ter a autoridade, nem mesmo o direito, de impedir o desenvolvimento de verdades novas, ou o ensino de teorias contrárias a uma política de partido, ou aos seus interesses particulares. (Ibid., p. 10) 
Não se trata de uma independência absoluta, porque os estabelecimentos deveriam depender da Assembleia dos Representantes do Povo.

O plano de educação de Condorcet, elaborado em Instrução Pública e Organização do Ensino, texto que fazia parte do Relatório sobre a Instrução Pública no Estado Francês, compreende 5 graus de instrução: a escola primária, a secundária, os institutos, os liceus e a sociedade nacional das ciências e das artes. Os objetivos da instrução pública nacional compreendem:

Facultar a todos os indivíduos da espécie humana os meios de proverem às suas necessidades, de conseguirem o seu bemestar; assegurar a cada um este bem-estar, torná-lo cônscio defensor dos seus direitos e esclarecido cumpridor dos seus deveres; garantir-lhe a facilidade de aperfeiçoar a sua indústria, de se habilitar para o desempenho de funções sociais a que tem o direito de ser chamado, de desenvolver completamente os talentos que recebeu da Natureza; estabelecer entre os cidadãos uma igualdade de fato e realizar a igualdade política reconhecida pela lei - tal deve ser o primeiro objetivo duma instrução nacional e, sob este aspecto, ela é para os Poderes Públicos, um dever de justiça. (Condorcet, 1943, p. 5)

A educação formal, por sua vez, deve:

Dirigir o ensino, de maneira que a perfeição das artes aumente a felicidade dos cidadãos e o bem-estar dos que as cultivam; que um maior número de homens se habilite ao desempenho de funções necessárias à sociedade, e que os progressos sempre crescentes dos conhecimentos abram uma fonte inesgotável de socorros às nossas necessidades, de remédios aos nossos males, de possibilidades de ventura individual e de prosperidade comum; cultivar, enfim, em cada geração, as faculdades intelectuais e morais e contribuir desta forma para o aperfeiçoamento geral e progressivo da espécie humana, derradeira meta que deve visar toda a instrução e este é, para o Poder Público, um dever imposto pelo interesse comum da sociedade e pelo da Humanidade inteira. (Ibid., p. 6)

Nota-se que Condorcet atribuía ao Estado o encargo de providenciar a educação do seu povo, pois, sendo ele composto pelos representantes da nação, o Poder Público, ao organizar e implementar um sistema de ensino, nada mais faria do que Justiça ao seu povo, tirando-o da ignorância para 
que, ao mesmo tempo, conquiste um bem-estar maior e contribua para o progresso da vida social e do aparato público. A educação e a melhora do indivíduo conduzem a uma melhora da sociedade. No que concerne ao interesse comum da humanidade inteira, mencionado ao final desta última citação, Condorcet entende que a vida humana tem como fim garantir a liberdade e a igualdade humanas das quais todo homem é depositário. Se há opressão e desigualdade, estas são fruto da ação humana e por isso mesmo podem ser superadas historicamente. Quando se realizar um modo de vida no qual se garantam tais ideais, cumprem-se os interesses da humanidade, ainda que a maioria dos homens não reconheça, por ignorância, tais interesses.

Condorcet previa em seu projeto uma espécie de formação continuada, que ele preferiu chamar de Segunda Educação. A ignorância à qual a população se encontrava tem como causa não apenas a falta da Primeira Instrução, mas também a inexistência de oportunidades para que os benefícios da educação elementar fossem conservados e desenvolvidos. Para enfrentar esta situação, a Segunda Educação atuaria em duas frentes: 1) abarcar todas as idades e aqueles que ainda não foram à escola na idade adequada; 2) não abandonar os indivíduos quando estes saem da escola. A Segunda Educação é tanto mais necessária quanto mais estreita foi a Primeira. (Cf. 1943, p. 8)

As Conferências Públicas, no projeto de instrução proposto por Condorcet, encaixam-se nesta modalidade de educação continuada do cidadão. As Conferências Públicas

Terão por objetivo principal as descobertas científicas, as experiências, as observações novas e os processos úteis às artes; e, por novo, entende-se aqui o que, sem sair dos limites duma instrução elementar, não está ainda colocado na classe dos conhecimentos comuns, dos conhecimentos universalmente adotados. (Ibid., p. 39)

Embora seu público alvo sejam as pessoas com certo grau de instrução, capazes de adquirir conhecimentos por si próprios, verifica-se que 
todas as pessoas podem participar das Conferências, conforme o próprio Condorcet deixa perceber ao enumerar as três vantagens desta formação:

\begin{abstract}
Esta espécie de publicidade, regulada de forma que não possa perturbar a ordem do ensino, teria três vantagens: - a primeira, a de procurar meios de ilustrar aqueles cidadãos que não puderam receber uma ilustração completa, ou que não a aproveitaram suficientemente e oferecer-lhes a faculdade de adquirirem, em qualquer idade, os conhecimentos que possam chegar a ser-lhes úteis, de promover que o bem imediato, que pode resultar do progresso das ciências, não esteja exclusivamente reservado aos sábios e à juventude: a segunda, que os pais possam ser testemunhas das lições dadas aos filhos; a terceira, enfim, que os jovens, postos, em certo modo, sob as vistas do público, tenham mais emulação e adquiram, desde novos, o hábito de falar com segurança, com facilidade e com correção, o que não poderão conseguir sem um certo número de exercícios solenes. (Ibid., p. 40-41)
\end{abstract}

As Conferências seriam ministradas pelos professores, que teriam a incumbência de oferecê-las uma vez por mês, preferencialmente aos finais de semana, para que um maior número de pessoas pudesse participar. Para tanto, os estabelecimentos de ensino seriam dotados de uma infraestrutura capaz de garantir uma aprendizagem significativa. Condorcet previa bibliotecas, gabinetes para os professores atenderem os estudantes, jardim botânico e agrícola. A eficácia de tal instrução não seria garantida pela simples exposição dos conteúdos, mas também pelo debate e pelo exercício das novas habilidades e das práticas de experimentação científica. Dessa forma, seria assegurado que os participantes entenderiam e reteriam os ensinamentos e suas faculdades intelectuais adquiririam atividade e força. (Cf. 1943, p.40-41)

Condorcet reconheceu que cada região demandaria uma Segunda Instrução com características próprias à sua geografia, às necessidades imediatas, à sua economia ou a outra atividade preponderante. Cidades onde houver Marinha ou Práticas de Pesca ensinar-se-ia a arte náutica; nos agrupamentos militares a explicação das leis e dos regimentos de defesa; técnicas de agricultura, a política, a construção, os primeiros socorros e a difusão dos novos conhecimentos conquistados com o empenho do espírito humano em progresso fariam parte deste programa geral. 
A Segunda Instrução, portanto, teria por fim "assegurar aos homens, em todas as idades, a facilidade de conservar os seus conhecimentos e de adquirirem outros novos” (Ibid., p. 10). No “combate à tirania, aos privilégios e superstição” (Ibid., p. IV), “para salvaguardar os direitos de liberdade e de igualdade para todos” (Ibid., p. XI), Condorcet vê na instrução universal e tão igual quanto possível um grande potencial para conduzir o homem a um aperfeiçoamento progressivo, de que resultará o aperfeiçoamento gradual da sociedade e o estabelecimento duma ampla igualdade entre os homens. Numa passagem do Esboço de um Quadro Histórico dos Progressos do Espírito Humano se elucida esta correspondência entre educação e progresso:

Os progressos das ciências e das artes asseguram os progressos da arte de instruir, que eles mesmos aceleram, em seguida, aquelas das ciências; e sua influência recíproca, cuja ação se renova sem cessar, deve ser colocada entre as causas mais ativas, as mais poderosas do aperfeiçoamento da espécie humana. (1993, p. 197)

Os progressos do espírito humano forneceriam o fio condutor para se fazer uma história com esperança em mudanças substanciais na sociedade. O progresso do mundo natural e social é fruto da ação humana racional visando à sua transformação.

Se é possível construir um futuro diferente, o progresso é a realização das idéias da razão. Deste modo, estabelece-se uma correspondência entre 0 desenvolvimento da razão, o aperfeiçoamento dos homens e a construção de uma sociedade mais feliz. (Condorcet, 1993, p. 8)

A função da escola, nesta visão, ultrapassa a de mero estabelecimento transmissor de saberes ao se firmar como locus de difusão do conhecimento, de convívio entre sociedade, professores e a ciência, de práticas sociais e científicas formadoras de um novo habitus no homem, que transformam o seu modo de ser, estar e pensar o mundo, com a esperança de que esses cidadãos que freqüentam o espaço escolar fundem um novo ethos que supere as contradições vividas e apresentadas por Condorcet no Relatório sobre a Instrução Pública no Estado Francês. 
O autor não é ingênuo quanto a este progresso pela educação. Ele sabe que este é um campo conflituoso, no qual há disputa de interesses e concepções, que parecem estar ausentes, por exemplo, no Curso de Filosofia Positiva, de Comte. Condorcet alertava para a separação das ciências e das artes daquilo que os espíritos mercantil e fabril estavam fazendo delas, isto é, conduzindo-as a uma racionalidade técnico-científica reduzida e prejudicial à vida do trabalhador e dos homens em geral. Este risco permanece nos dias de hoje, pois a maioria dos discursos dos gestores, sejam eles da educação ou de outros segmentos, pautam e apregoam os princípios de eficiência, competências, lucro e poder. A formação integral do homem não poderia se reduzir à educação do homo faber. (Cf. Sanchez Gamboa, 2003, p. 85). Condorcet aponta não para uma certeza, mas para uma esperança num futuro melhor conquistado pelo progresso das ciências e das artes e do espírito humano. É defendido o uso reflexivo e crítico da razão sobre todas as coisas, inclusive dela sobre si mesma.

Há análises defendendo que o projeto de Condorcet foi derrotado, em detrimento de outros projetos mais parciais ou com outros acentos políticos. Outros estudos consideram que o plano de Condorcet, mesmo que não implementado e substituído por outros, permaneceu como pano de fundo para a elaboração de novas propostas. Em 1793 é apresentado o projeto de Le Peletier, que expressa o ponto de vista jacobino e quando este partido esteve à frente da Revolução, Condorcet foi perseguido e preso, sob suspeita de sua ligação com os girondinos. E em 1794 o plano aprovado foi o de Joseph La Kanal, que serviu de parâmetro para a difusão do ensino elementar na França e se seguiu até os tempos de Napoleão.

Uma justiça deve ser feita a Condorcet. Não se nega que o autor era um porta voz da burguesia liberal contra os interesses da monarquia absolutista, contra o obscurantismo religioso e todos os entraves que estas duas instâncias acarretavam às novas formas de pensamento e da vida social. Condorcet usa termos característicos aos textos de educação do liberalismo: fala de dom, desenvolvimento de habilidades individuais, de que nem todos alcançarão os níveis mais altos de instrução, embora esta não 
deva ser negada a nenhum cidadão. No entanto, não se pode comparar as propostas de Condorcet com outras propostas do mesmo período, ou ainda às posteriores, devido à maior abrangência de seu plano. Ele prevê um projeto de formação integral do homem que vai muito além dos interesses imediatos da burguesia e da indústria. Aliás, foi radicalmente contra a reduzir a instrução aos aspectos técnicos e mecânicos da vida profissional.

Contra o discurso de que o plano de Condorcet seria apenas uma propaganda ideológica e jamais seria posto em prática, uma vez que não interessava à burguesia estender a mesma educação igual e universal para todos os cidadãos, com a finalidade de estabelecer a igualdade entre os homens, pode-se dizer que tal afirmação de pronto não se justifica. E devido aos seguintes motivos: 1) apesar de ter sido o plano aprovado pela Assembleia em 1792, ele não teve tempo suficiente para ser executado, uma vez que o próprio Condorcet perdeu seu espaço com a tomada de poder pelos jacobinos; 2) outros projetos de instrução pública com menor abrangência foram aprovados logo em seguida à queda de Condorcet e mesmo que estes outros planos tenham tido alguma influência do projeto de 1792, não se tratava genuinamente do projeto original e nem foram conduzidos por Condorcet.

O espaço deste artigo não se propõe a emitir uma resposta à acusação acima, muito menos pode entrar nos méritos da intenção do autor quando pensou, redigiu seu plano e lutou para que ele fosse aprovado. Caberia, posteriormente, aprofundar os estudos para se apontar os limites da proposta de Condorcet dentro do conjunto dos acontecimentos e das ideias correntes no contexto em questão, ou ainda verificar em que medida a sua proposta influenciou diretamente outros tantos planos que surgiram e foram concretizados naquele momento, para se verificar qual modelo de escola e educação tais propostas deram forma. 
Dois programas liberais em confronto: conferências públicas e escola da família

O que se segue agora é uma breve comparação entre duas propostas de Segunda Instrução que se inserem no âmbito do liberalismo: as Conferências Públicas e o programa Escola da Família, do governo do Estado de São Paulo. Acima fora anunciado que existem diferenças qualitativas entre planos de educação pertencentes a um mesmo pensamento político e econômico. Mesmo que haja uma distância de dois séculos, ainda vivemos no mesmo paradigma originado pelas Revoluções Industrial e Francesa. Enfim, com esta comparação pretende-se mostrar que é possível criticar propostas (neo)liberais no interior da própria tradição liberal.

Vários aspectos das Conferências Públicas e do papel que ela desempenharia naquilo que Condorcet chamou de Segunda Instrução foi descrito no item anterior. Faz-se necessário, neste momento, destacar os objetivos e as principais características ${ }^{2}$ do programa Escola da Família. Trata-se de um programa criado em 2003, juntamente com outros do mesmo perfil em outros Estados brasileiros, mas incentivado desde a metade do segundo mandato do ex-presidente Fernando Henrique Cardoso. Colocado em ação no governo Alckmin, o programa foi bastante reduzido na gestão José Serra sob o argumento de a economia de gastos seria aplicada na contratação dos segundos professores para as salas de aula, promessa de campanha não realizada durante sua gestão.

O programa se insere numa série de outras ações que tem como fim contribuir para a criação de uma cultura de paz, despertar potencialidades e desenvolver hábitos saudáveis junto aos jovens que vivem no Estado de São Paulo e tem como objetivo a abertura das escolas da rede estadual aos finais de semana, para que sejam transformadas em centros de convivência, com

\footnotetext{
2 Referências obtidas atrás do site oficial do programa e do site da Unesco: http://www.escoladafamilia.sp.gov.br/, $\quad$ acesso em 10/06/2008. http://www.escoladafamilia.sp.gov.br/destaques.html, acesso em 10/06/2008. http://www.unesco.org.br/areas/dsocial/institucional/projetos/culturapazprojetos/culturapaz projetos/mostra_padrao, acesso em 10/06/2008.
} 
atividades voltadas às áreas esportiva, cultural, de saúde e trabalho. A proposta visava atrair não somente os estudantes, mas também os pais e toda a comunidade vizinha às escolas.

Trata-se, portanto, de uma luta para que as escolas se tornem espaços de uma nova cidadania e de relações sociais, numa tentativa de que a consolidação destas novas práticas colabore para reverter o quadro de violência que atinge várias localidades do Estado. Foi realizada uma pesquisa entre os jovens para saber quais áreas de interesse poderiam fazer parte do programa e o resultado apontou para os seguintes assuntos: “orientação profissional, aprendizado de informática e línguas estrangeiras, conteúdos ligados à educação sexual e prevenção ao uso de drogas, além de ter sido solicitado o estímulo à presença de pais e familiares na escola"; que posteriormente foram agrupados nas áreas temáticas de: Inclusão Social e Redução da Pobreza; Direitos Humanos, Racismo, Discriminação e Xenofobia, Cultura de Paz, Filosofia, Ética, Esporte, Juventude e Transformação Social.

O Escola da Família ainda conta com mais duas características: o voluntariado e as parcerias. Não são somente os educadores profissionais e contratados pelo Estado que atuam no programa. Além dos voluntários, há os educadores universitários, isto é, graduandos de diversas áreas que se inscreveram para participar do programa numa das áreas temáticas, que terão $50 \%$ do valor das suas mensalidades (desde que este $50 \%$ seja no máximo R\$ 267,00) custeadas pelo Estado, em troca de 16 horas de atividades aos finais de semana, nas escolas onde se realizavam o programa. Há ainda parcerias com empresas, fundações, ONG’s, sindicatos e outros, para a realização de diversos trabalhos, como por exemplo, a capacitação de coordenadores e monitores do programa.

Na proposta de instrução pública de Condorcet todo o custeio da educação é previsto para o Estado e o próprio ensino, além de universal, é gratuito. De alguns anos para cá, vemos um Estado que busca parcerias em vários setores considerados essenciais para a vida pública, como saúde, 
educação, transporte, geração de energia, telecomunicações etc., enquanto que em outros setores o Estado é o grande parceiro, como na ajuda aos bancos falidos, no socorro ao agronegócio, na manutenção da opção pelo transporte rodoviário e em tantas outras situações.

Entre as proposições do programa Escola da Família, não se encontram três pontos fundamentais que Condorcet atribuía aos objetivos das Conferências Públicas: 1) o mais importante motivo das Conferências, além de espaço de convivência e integração das pessoas, era a divulgação dos saberes científicos, aproximando a população daquilo que o esforço da capacidade humana conquistava e que poderia resultar em benefício para a vida dos cidadãos e para a vida social, juntamente com o debate sobre o aperfeiçoamento do viver civil; 2) preparar a infraestrutura da escola para o funcionamento adequado dos trabalhos de experimentação científica e de divulgação do conhecimento, tais como bibliotecas, jardins, ou, atualizando a linguagem, laboratórios; 3) a participação nas atividades das Conferências permitiria, de alguma maneira, que os pais acompanhassem aquilo que é ensinado aos seus filhos na Escola. Notamos que os objetivos das Conferências Públicas e o seu alcance eram bem mais ambiciosos do que o Escola da Família.

\section{Conclusão}

A partir do se apontou no decorrer do texto, se constata as contradições do estado capitalista e da sua mais representativa teoria, isto é, o ideário liberal e suas nuances ao longo da história. Nesta conjunção, estado capitalista e liberalismo, os únicos processos que merecem cuidado e continuidade são aqueles que garantem a acumulação do capital, a reprodução, aperfeiçoamento e adaptação do modo de produção e a manutenção da histórica e injusta dos mais variados tipos de desigualdade. Sem questionarmos e superarmos as prioridades do atual sistema, qualquer reforma que tenha por objetivo eliminar as desigualdades e as injustiças, de 
tornar o homem livre de qualquer tirania e fazer dele o cidadão apto para tomar frente ao processo democrático se torna ilusória.

Diante disso, como entender a postura de Condorcet, no interior do pensamento liberal? Seu projeto tinha como fim contribuir para o aperfeiçoamento dos homens, para que, ilustrados em sua inteligência e capacidade de julgar, pudessem progredir rumo a uma outra sociedade, a um outro ethos. Este era o estado de espírito dos Iluministas, em forte oposição aos Medievais. Do homem pecador e incapaz, ao homem livre e motor dos rumos da humanidade. Era a crença na perfectibilidade humana.

As posteriores críticas e acontecimentos históricos dos séculos XIX e XX apontaram para os limites de tais crenças. A razão foi reduzida à sua dimensão instrumental, a educação não chegou indistintamente a todos, as desigualdades não foram diminuídas nem o homem conheceu o que é a liberdade de fato. Aponto dois aspectos da produção de Condorcet que nos ajudam na crítica do próprio modelo liberal e indicam ainda caminhos que considero válidos no questionamento deste ideário.

Quando Condorcet propõe as Conferências Públicas ele demonstra uma preocupação bastante singular com a educação progressiva dos homens. Não é apenas no momento da escolarização que se aprende ou se está em idade apta para adquirir algum conhecimento. As descobertas científicas, as produções culturais e em outros campos acontecem a todo o momento, servem muitas vezes a diferentes interesses. Ao terminar sua escolarização, o homem é abandonado à própria sorte para continuar sua educação.

E em nossa sociedade, continuar a educação quer dizer consumir um produto educacional. Há um mercado amplo de pós-graduação, de cursos de idiomas ou cursos profissionalizantes que se prestam aos mais variados fins. E quando há estimulação para que os homens continuem se formando, em grande parte os apelos são mercantis e instrumentais, atitudes frontalmente contestadas por Condorcet: o cidadão a ser continuamente formado é aquele que contribuirá para melhorar a sociedade e neste quesito o fim mercantil e 
a redução da razão ao seu aspecto técnico não são suficientes. E esta formação contínua, na visão do autor, não será entregue a um parceiro ou a voluntários, mas se trata de uma política de Estado para a educação, executada por profissionais específicos e devidamente preparados para tal, mas com a devida liberdade política e ideológica para ser realizada.

Um segundo ponto nos é remetido quando se recorda o que Condorcet espera das Conferências Públicas: deixar os homens em contato com as novas descobertas do engenho humano e que estes esclarecimentos os levem à superação de um quadro histórico de desigualdade e injustiça. Ora, fazer com que se conheça é munir a inteligência de meios para se atuar mais criticamente numa sociedade. Por isso sempre houve um controle muito forte do conhecimento e do seu acesso, não apenas nas sociedades fechadas, mas também nas sociedades ditas abertas, como a nossa. Fazer com que a Escola se torne um centro de referência não só da instrução escolarizada, mas também da Segunda Instrução, é potencializá-la como um dos meios de transformação social. É apostar que, se o progresso é possível, possível também é a transformação da sociedade.

Para além de Condorcet, reafirmando as possibilidades de superação dos entraves para o progresso humano e para a perfectibilidade social, é preciso reconhecer que à sociedade em que vivemos é inerente o caráter contraditório, o funcionamento dinâmico e por isso mesmo é possível de ser entendida dialeticamente. (Cf. Saviani, 2003, p. 92). Por ser uma sociedade em transformação e em constante movimento, suas estruturas devem ser entendidas como historicamente construídas e não dadas a priori. Portanto, se tais estruturas forçam a educação para reproduzi-las, é possível que a educação que busca a superação das desigualdades produzidas por esta sociedade interfira, num processo não-mecânico, mas dialético, na sua transformação. É o que Saviani chama de categoria da ação-recíproca,

ou seja, que a educação é, sim, determinada pela sociedade, mas que essa determinação é relativa e na forma de ação recíproca o que significa que o determinado também reage sobre o determinante”. (2003, p. 93). 
As Conferências Públicas, na proposta de Condorcet, pretendiam atuar sobre as deficiências educacionais de sua época, como também aproximar os homens das conquistas alcançadas pela razão humana e ainda na superação de determinadas visões de mundo que faziam do homem escravo e ignorante. Pode-se dizer que Condorcet, ao ter em mente esta possibilidade, entende a sociedade como dinâmica e capaz de mudanças, mesmo que não usando conceitos da tradição marxiana, como contradição, ação recíproca e transformação, que lhes são posteriores.

Concluo dizendo da satisfação e da importância de se ler os pensadores chamados de clássicos, fundadores dos grandes ideários do mundo ocidental. A partir de Condorcet, por exemplo, vislumbramos a crítica do próprio modelo liberal que se desenvolveu ao longo dos séculos XIX e XX: uma educação livre, continuada, próxima às conquistas do engenho humano, sem submissão ao poder político ou religioso, mas nem por isso apolítica ou neutra, custeada pelo Estado e oferecida gratuitamente aos seus cidadãos. Estes são alguns aspectos que podemos buscar em Condorcet com grande proveito, pensador republicano e democrático, defensor da formação de um cidadão que realizasse cada vez mais e melhor as ideias de República, Democracia, Liberdade e Igualdade social.

\section{Referências}

ABBAGNANO, Nicola; VISALBERGUI, Aldo. História de la pedagogia. México: Fondo de Cultura Econômica, 2002. 709 pp.

CONDORCET, Jean Antoine Nicolas Caritat, marquês de, (1743-1794). Esboço de um quadro histórico do desenvolvimento bumano. Campinas-SP: Editora da Unicamp, 1993. 205pp.

- Instrução pública e organização do ensino. Porto: Livraria Educação Nacional, 1943. 127pp.

SÁNCHES GAMBOA, Sílvio. A globalização e os desafios da educação no limiar do novo século: um olhar desde a América Latina. In: LOMBARDI, José Claudinei (org.) Globalização, pós-modernidade e educaşão: história, filosofia e temas transversais. $2^{\mathrm{a}}$ Ed. Campinas-SP: Autores Associados / HISTEDBR, Caçador-SC: UNC, 2003. 234pp. 
SAVIANI, Dermeval. Pedagogia histórico-crítica: primeiras aproximações. $8^{a}$ Ed. Campinas-SP: Autores Associados, 2003. 153 pp. 